\title{
DE COMO SE EXPRESSAM CONVERSAS E TRAVESSIAS DESMEDICALIZADAS: trajetórias no entre de uma pesquisa
}

\author{
Anelice Ribetto \\ Raquel Rosa Reis Monteiro
}

\section{Resumo}

Este texto pretende dar a ver parte de um caminho investigativo que compõe a produção de uma pesquisa. Os trajetos de formação por entre conversas e experiências são os passos fundantes que movimentam o pensamento de duas autoras. Trata-se de uma escrita que problematiza a produção da norma encarnada as trajetórias estudantis no espaço da Sala de Recursos (e para além dela), trajetórias essas marcadas por olhares clínico-institucionais na escola. Assim, trazemos escritas atravessadas pela experiência como possibilidade de pensar o que nos passa na educação. Tais travessias ajudam-nos a ganhar caminhos na produção de encontros outros desprovidos de normas definidas pelo saber médico, mas abastados de astúcias que por meio de múltiplas linguagens, criam um sentido outro (talvez menos técnico e mais sensível) na sala de recursos multifuncionais junto a trajetórias singulares que colocaram de pé uma pesquisa.

Palavras-chave: educação especial; sala de recursos; medicalização; travessias.

\section{HOW CONVERSATIONS ARE EXPRESSED AND DEMEDICALIZED} CROSSINGS:

trajectories in between research

\section{Abstract}

This text intends to show part of an investigative path that composes the production of a research. The training paths between conversations and experiences are the founding steps that move the thoughts of two authors. It is a writing that problematizes the production of the incarnated norm the student trajectories in the space of the Resource Room (and beyond), walking these marked by clinical-institutional views at school. Thus, we bring writings traversed by experience as a possibility to think what happens to us in education. Such crossings help us to gain paths in the production of encounters, others without norms defined by medical knowledge, but rich in cunning that, through multiple languages, create a different meaning (perhaps less technical and more sensitive) in the resource room next to singular trajectories that set up a research. Keywords: special education; resource room; medicalization; crossings.

\section{CÓMO SE EXPRESAN LAS CONVERSACIONES Y CRUCES} DESMEDICALIZADOS:

Resumen

Este texto pretende mostrar parte de un camino investigativo que compone la producción de una investigación. Los caminos formativos entre conversaciones y experiencias son los pasos fundacionales que mueven el pensamiento de dos autores. Es una escritura que problematiza la producción de la norma encarnada en las trayectorias del estudiante en el espacio de la Sala de Recursos (y más allá), recorriendo estas marcadas por miradas clínico-institucionales en la escuela. Así, traemos escritos atravesados por la experiencia como posibilidad para pensar lo que nos pasa en la educación. Tales cruces nos ayudan a 
ganarnos caminos en la producción de encuentros, otros sin normas definidas por el conocimiento médico, pero ricos en astucias que, a través de múltiples lenguajes, crean un significado diferente (quizás menos técnico y más sensible) en la sala de recursos al lado de trayectorias singulares que configuran la investigación.

Palabras clave: educación especial; aula de recursos; medicalización; cruces.

\section{PASSOS DE ABERTURA: MOVIMENTOS CONVERSANTES- DESMEDICALIZANTES}

Esta escrita nos guia a uma reflexão que começou a partir de encontros na escola para tecer um caminhar investigativo que compõe uma pesquisa. Os trajetos de formação por entre conversas e experiências são os passos fundantes que dão movimento a nosso pensamento que se pergunta sobre a produção da norma encarnada as trajetórias estudantis no contexto da sala de recursos multifuncionais (e para além dela). Caminhares ditos reprovados, marcados por olhares clínicos e institucionais, olhares que cotidianamente reprovam a diferença na escola.

$\mathrm{Na}$ travessia de produção da pesquisa nos movimentamos por um caminho que difere dos modos habituais como se tem percebido aquilo que é anunciado sobre o outro, aquilo que se fundamenta no que é estabelecido como norma na educação e que é legitimado por diagnósticos médicos aos sujeitos ditos especiais cuja trajetória quase sempre é definida pela necessidade de complementação na educação pelas vias do caminho do atendimento da sala de recursos, espaço esse que assume, geralmente, uma lógica técnica para lidar com a falta daqueles e daquelas que são pensados só num único sentido: o de insuficiência.

Apostamos como possibilidade epistemo-metodológica-política, escrever/dizer aqui sobre efeitos singulares que nos passam e que são parte de travessias produzidas entre caminhares conversantes, "[...] pois nunca se sabe onde uma conversa pode levar" (LARROSA, 2003, p. 2012) na prolongação de sentidos que abrem outras passagens, outros processos educativos sempre em movimento. Como escrevem Nicastro e Greco (2012, p. 130): a "[...] trayectoria continua en otro lugar [por isso] seguimos habitados por otros, habitando a otros".

Nessa perspectiva, esse trabalho evoca a construção de caminhos que não documentam a vida. Tais efeitos de experiências aqui narrados, inscrevem nossa entrada - como investigadoras - no meio da travessia do chamado campo da inclusão. Pois, como conta Larrosa (2016, p. 27) "[...] sempre se começa pelo meio de alguma coisa, dentro de alguma coisa", já que ninguém faz sua trajetória sozinho. Assim, fazemos referência às trajetórias e tentamos ensaiar também o que Skliar (2014a, p. 26) define como travessia, algo que "[...] é a duração da continuidade. Durante a travessia há trajetória, uma trajetória que somos nós mesmos". A travessia remete-nos então a "[...] algo que mora no meio. Entre" (SKLIAR, 2014a, p. 27). Bem como a conversa, que nos possibilita pensar "[...] sobre o que nos acontece naquilo que fazemos" (SKLIAR, 2014a, p. 40).

Fiéis ao uso conceitual da conversa expomos, aqui, os passos produzidos pelos próprios movimentos da vida imbricada aos desassossegos da experiência. Problematizamos ainda a insistente produção de discursos técnicos e jurídicos oriundos principalmente de políticas inclusivas com efeitos sobre as trajetórias estudantis, que — sob as lentes da norma — perpetuam a lógica do outro como mesmo, como alguém a ser reformado, nomeado, diagnosticado, incluído, definido e aniquilado. Finalmente, trazemos travessias astuciosas de uma experiência de praticantesdançantes: caminhadas ensaiadas na Sala de Recursos Multifuncionais. Encontros que nos atravessaram e que narram efeitos de uma conversa ali produzida. 


\section{ENSAIANDO EXPERIÊNCIAS IMPLICADAS A TRAJETÓRIAS NUMA PESQUISA}

Revisitando nossa caminhada, convém sublinhar que a irrupção de experiências dessas duas autoras imersas no campo de estudos da inclusão foi movimentada ao passarmos a ter experiências significativas com pessoas ditas com deficiência nos cotidianos escolares, pessoas com outras formas de aprender e chamadas habitualmente de especiais, pessoas que foram desenhando uma trajetória de formação a partir de conversas inquietantes, deslocadoras com professores, estudantes, famílias. Foi por meio das relações educativas hibridizadas às conversas que emergiram interpelações e uma pergunta basilar que atravessou nossa pesquisa dando a ver potência de um caminho metodológico: como conversar com estudantes que nos mostram outras formas de existir?

$\mathrm{Na}$ escola eu tinha contato com muitos estudantes e cotidianamente conversava com eles, mas, agora, mergulhada na multiplicidade de vidas outras emergindo nesse espaço educativo, comecei a pensar em como poderia conversar com estudantes que nos mostram outras formas de existir que não são as que esperamos, as que são dadas pela norma, as que se pautam pela mesmidade. Mas, quais são as formas de estudantes que esperamos, ou melhor: por que esperamos o que esperamos nos estudantes? (Diário de Trajetórias)

Eis o problema que se apresentou para nós como um potente campo investigativo: como conversar com trajetórias não dadas pela norma? Tais trajetórias se resumem a um diagnóstico normativo? A norma legislaria e vigiaria a vida sentenciando a incapacidade de uma existência?

Em uma tarde aparentemente comum na escola, converso na sala [...] com um jovem que foi à escola a meu pedido por meio de contato telefônico, visto que sua ausência se caracterizaria em abandono escolar. Completados seus 17 anos de idade, cursando o oitavo ano do ensino fundamental (fazendo tratamentos médicos desde os treze anos de idade quando fora diagnosticado com deficiência intelectual), o jovem, tímido e calado afirmou com muita segurança o desejo de não mais estudar. $\mathrm{Na}$ ocasião, seus responsáveis participaram dos momentos iniciais da conversa, não demonstrando mais domínio sobre a segura decisão do rapaz em deixar a escola. Conversando em particular com o jovem, tentei entender o que o fazia desistir de estar ali, pois, parecia ser tomado por um sentimento de aflição, angústia ou sofrimento no que se referia à simples hipótese de pensar em permanecer na escola. Ao buscar uma aproximação com o jovem para iniciar a conversa, perguntei-lhe sobre outras coisas e inclusive de sua namorada, (já que de acordo com os responsáveis estava namorando). Sentindose mais à vontade na conversa, perguntei posteriormente sobre seu "sumiço" das aulas. A resposta veio desterritorializando-me. Ele me olhou com toda a sinceridade que um olhar pudesse expressar e disse quase que como um grito engasgado: 'Eu não aprendo! Já sei que nunca vou aprender nada mesmo! Eu não sei ler, não preciso estar aqui!" Essas palavras me atravessaram com uma intensidade descomunal, intensidade de quem descobre naquele momento uma violência na trajetória formativa daquele estudante, trajetória que, talvez, tenha sido fabricada para encerrar-se durante muito tempo na escola, trajetória que "bagunçava" as práticas educativas padronizadas por não se enquadrar em um sujeito "aprendente". Ele foi desistindo da escola estando nela... Ele escrevia... copiava o que lhes diziam para copiar (vi seu caderno), penso! Meu pensamento se refaz: resistiu por mais de oito anos de escolarização copiando para tornar-se 
como os demais... copiava, talvez para não destoar da maioria... cansou-se de ser o outro que não era ele mesmo! Cansou-se de "bagunçar" a cena congruente da educação. Como um ato de resistência, desiste de ser o ser "não aprendente" como tanto ouviu num lugar ironicamente nomeado como espaço para aprender. Desiste da escola, insiste em ser apenas ele. (Diário de Trajetórias)

Entre trajetórias conversativas e imprevisíveis, implodiram-nos pensamentos acerca da marca da "anormalidade" ou "incompletude" que obsessivamente define o corpo do outro de forma absolutiva: é o diagnóstico aquilo que representa um caminho para aprender? É ele que desnuda um caminho de cura, ou é ele a constatação da impossibilidade de produzir um caminho outro, não inscrito pelos limites da norma na escola? É o diagnostico o percurso que garante uma trajetória de formação ou é ele "um passaporte para continuar a ter o direito de aprender na escola"? (MOYSES, 2001, p. 10). É o diagnóstico algo que apresenta aos sujeitos outro espaço de pertença ou um mesmo caminho de perpetuação da falta? Parece-nos que há uma série de definições para avaliar estudantes seguindo a lógica inventada de um potencial cognitivo, medicalizado: alunos aprendentes e não aprendentes, com deficiência e eficientes, lentos e hiperativos, com necessidades especiais, incluídos, excluídos etc.

Essas perguntas evocam necessariamente a outras questões que se expandiram para além da pesquisa: o que é aprender? Por que os alunos que não aprendem saberes majoritariamente escolásticos, definidos pelas secretarias de ensino são vistos (numa única direção possível de ser) como "deficientes" e por isso, quase sempre marcados por discursos medicalizados que diagnosticam a falta? Existiria um sentido único configurado por formas idênticas de aprendizagem que irremediavelmente precisa ser documentado atestado como um suposto mal, como justificativa para a não aprendizagem de um estudante? Não haveria causas pedagógicas para além da máxima declarada de anormalidade nos contextos educativos? O discurso diagnostical da falta ou ausência para aprender apontaria quais possibilidades outras nas cenas escolares? Pensemos com Moysés (2001, p. 46):

Entende-se, assim, que a ênfase seja dada ao que a criança não tem, ao que ela não sabe, aquilo que lhe falta. Ё um olhar voltado para a carência, para a falha da criança. Ё como se a criança que está sendo avaliada precisasse se encaixar nas formas de avaliação que o avaliador, supostamente, inteligente conhece [...] A avaliação pode ser vista como uma perseguição ao defeito da criança, sim, pois com certeza o defeito só pode estar localizado nela, já que vivemos em um mundo em que todos pretensamente tem as mesmas oportunidades etc... etc...

Colocando as lentes de Moysés, pensamos que, rotulados, tais sujeitos externalizam o preconceito que incorporaram e que evidenciamos na frase que compõe a experiência registrada no Diário de Trajetórias: "Eu não aprendo! Já sei que nunca vou aprender nada mesmo! Eu não sei ler, não preciso estar aqui!". Uma mesma avaliação pautada sempre nas mesmas normas clínicas, medicalizadas, vai produzindo uma mesma trajetória estudantil quando o “[...] diagnóstico não é bastante para resolver o problema, porém é suficiente para acalmar os conflitos de um aluno que não aprende na escola" (MOYSÉS, 2001, p. 47). O diagnóstico lhe confere, inclusive, aptidão para inscrição num lugar produzido na escola para receber trajetórias consideradas desviantes devendo, por isso, ser complementada —: a sala de recursos multifuncionais.

Um fato que nos chama atenção e que também é sinalizado por Moysés (2001) é que estudantes já marcados como não aprendentes ou "deficientes" já têm passado por um sem número de profissionais de saúde que institucionalizam diagnósticos normativos sem que, isso, 
necessariamente, promova atenção e disponibilidade de professores para mudanças em seus projetos didáticos de ensino e, menos ainda, tais laudos jamais representaram, até hoje, a possibilidade de pensar a diferença como condição de existência de toda e qualquer trajetória estudantil. E é a Greco e Nicastro (2012) e Moysés (2001) a quem damos voz para pensar os caminhos de trajetórias educativas tão singulares, mas excessivamente definidas pelo olhar uniforme da norma nos cenários educativos.

O pensamento do conceito de trajetória das autoras Greco e Nicastro (2012) nos foi/é muito caro para o agenciamento do conceito de conversas e encontros produzidos por nós na pesquisa, por isso, cabe-nos também conversar com ele:

\begin{abstract}
Al hablar de trayectoria nos referimos a un recorrido, un camino en construcción permanente, que tal como lo señala Ardoino (2005) va mucho más allá de la idea de algo que se modeliza, que se puede antecipar en su totalidad o que se lleva a cabo mecánicamente respondendo sólo a algunas pautas o regulaciones. No es un protocolo que se sigue, preferimos pensarlo como un itinerario en situación (GRECO, NICASTRO, 2012, p. 23).
\end{abstract}

Asseveram as autoras que o conceito de trajetória supõe algo que não se pode fabricar, regular, os caminhos singularmente se constroem e se afirmam com particular potência. A palavra trajetória nos remete a uma maneira singular de entender a própria formação, nos lembra um caminhar, um durante, um caminhar sempre em curso. No caminho o caminhante se produz e faz caminho ao andar com outros numa processualidade que não pode ser fabricada. Por isso, não se pode pensar em trajetória apenas no sentido linear, ordenado, medicalizado. Dizem as autoras que, ao pensarmos em trajetórias, precisamos refletir "[...] quién o quiénes estan alli, las tramas que se configuran" (NICASTRO, GRECO, 2012, p. 24). As autoras nos permitem refletir também outra questão: o que as trajetórias não são: certamente não são um espaço para fazermos algo de alguém, tão pouco se constituem um único caminho para os mesmos estudantes, e menos ainda, são algo que possa ser pensado apenas em um plano institucional.

Difícil e ao mesmo tempo desafiante é tecer também com Moysés (2001) uma perguntaconversa que nos lembra a impossibilidade de determinar o potencial de alguém, segundo parâmetros atestados pelo olhar médico. Eis a pergunta: “[...] é possível avaliar o potencial intelectual de alguém?” (MOYSÉS, 2001, p. 35). E a própria autora nos ajuda nessa discussão, entendendo ser improvável que o potencial de um estudante seja representado como uma medida única, expressão total do potencial de um sujeito, mas é, em tal medida, apenas um substrato inicial desse potencial, já que "[...] não será jamais um reflexo linearmente unívoco do potencial" (MOYSÉS, 2001, p. 36), ou seja, “[...] não temos acesso [absolutamente] ao potencial das pessoas, apenas a [formas de] expressão desse potencial”. Por isso, inferimos que não há uma inteligência considerada grandíloqua a ser desenvolvida e medida por especialistas como algo determinado apenas pelo biológico. A cognição de alguém respeita também suas condições concretas de vida, suas potencialidades, histórias etc. Para além disto, percebemos com Moysés (2001) que há uma barreira imposta cultural e política que transforma em anormalidade toda desigualdade de pensamento para normatizar uma trajetória, dando razão apenas ao pensamento clínico, científico. Neste sentido, a forma impregnada pelo pensamento científico, medicalizado, nos parece ser insuficiente para avaliar o momento do processo educativo e "o saber" dos estudantes com trajetórias outras na escola básica, já que quase sempre seu aprendizado — configurado a normas guiadas por padronizações pedagógicas clínicas — se guiam pelos saberes oficiais específicos como, 
por exemplo, leituras e escritas medidas pela escola regular e, também, por ela institucionalizadas e não a outras possibilidades de pensamento para além do campo cientificizado.

Retomamos a pergunta que nos moveu na pesquisa: como conversar com estudantes com trajetórias outras? Deslocamo-nos ainda com outras questões: as trajetórias podem ser nomeadas, uniformizadas, visto que são singulares? A relação educativa se limitaria a uma linguagem técnica?

\section{EXPERIÊNCIAS CONVERSANTES E POLÍTICAS DE INCLUSÃO: CAMINHARES ENTRE A NORMALIDADE E TRAJETÓRIAS OUTRAS}

A relação vivenciada com estudantes, professores, pais, juntamente com os dilemas que nos passam, ou ainda os acontecimentos que consideramos, por vezes, menos importantes, guardam consigo uma potência que nos movimenta a pensar a conversa. Não é casual que Skliar (2014b) aponte que a educação é um lugar de conversação, mas não qualquer conversação. Uma conversa, para este autor, é conversa quando é baseada no estar juntos supondo, sobretudo, relações de afetação, “[...] tensões, desentendimentos, incompreensões, impossibilidades, perdas de argumento, perguntas de um lado apenas, respostas que não chegam" (SKLIAR, 2011, p. 29). A conversa não pode supor um código formal e assevera ele que "[...] estamos demasiadamente habituados a pensar a conversa como um idílico [...] particularmente caracterizado pela harmonia de vozes, dos corpos, das mentes" (SKLIAR, 2011, p. 29).

Essa foi a pergunta inicial que movimentou nosso trabalho a pensar, com Skliar (2014b), "como conversar?". Como a atitude de pensar o outro para conversar se reflete num encontro para além de atendimento no sentido clínico dado a essa relação? Habitualmente, diz o autor, há preocupação em todo o mundo educativo que pressupõe o educar como um saber acerca do outro, saber esse que opera como norma fundamental para a produção das relações educativas. Perguntas como: "quiénes son o cómo son" (SKLIAR, 2014b, p. 81) os outros, vão comumente sugerindo respostas perfeitas para definir os estudantes. Sobre isso o autor, também ancorando seu pensamento a Garcia Molina (2008 apud SKLIAR, 2014b, p. 81), indaga: "No será que tanta previsión y tanta planificación, que tantos motes de designación, nos hacen perder lo infinitamente atractivo que resulta iniciar una conversación inédita con alguien que no conocemos"?

O conceito de normalidade tornado pétreo na educação é apresentado por Skliar (2005, p. 15) como algo que "no es más que la imposición de una supuesta identidad única, ficticia y sin fisuras de aquello que es pensado como lo "normal", e se faz potente para percebemos como a norma opera, atentando-se aos "desvios" e descrevendo detalhes dos outros nomeados como anormais: uma anormalidade inventada, guiada por uma certa obsessão pelo outro para "[...] tornar o outro algo mais parecido a um de nós” (CLÍMACO, 2010, p. 12). Júlia Clímaco (2010) também destaca que esse conceito foi construído a partir de regras universais que padronizavam as pessoas e demarcavam os lugares que o outro deveria ocupar, instituindo a concepção de normalidade como única forma de existência. Percebemos que a instauração da norma e sua institucionalização nas relações educativas se dá a partir da definição, nomeação e categorização dos corpos, mentes e línguas de um outro que é traduzido pelas leis que lhe proíbem a diferença e legitimam o que é idêntico.

Encontramos pertinência entre as conexões do conceito de normalidade e o de conversas para pensar as trajetórias singulares na escola a partir da aposta de encontros entre professores e estudantes na Sala de Recursos, fundamentados na pergunta que nos atravessou: como conversar com trajetórias outras? A conversa certamente não poderia supor, ali, apenas um código funcional, instrumental, mas uma experiência singular que nos coloca num lugar para falar a linguagem da

Revista Teias v. 22 • n. 66 • jul./set. 2021 • Seção temática Programas e práticas pedagógicas na educação especial e inclusiva 
experiência. Assim, expandimos nosso estudo pensando em como a linguagem política e educacional opera na Sala de Recursos, na produção de trajetórias, ao fazer referência aos sujeitos que ali habitam e ao padronizarem trajetórias educativas, pois:

[...] boa parte dos discursos sobre inclusão — sobretudo aqueles que pretendem capturar todas as configurações possíveis entre nós e eles, ou entre um e outro [...] afirmam a convivência, porém com a condição de que [...] o contato se mantenha a uma distância prudente, muitas vezes matizada por palavras de ordem, tais como tolerância, ou aceitação ou reconhecimento do outro, talvez porque ali não exista relação, mas um excesso de distância, ou indiferença. (SKLIAR, 2011, p. 31).

Aguçadas na reflexão pelas obras que nos acompanharam, revisitamos a Política Nacional de Educação Especial na Perspectiva da Educação Inclusiva (2008) e o Manual de Orientação: Programa de Implantação de Sala de Recursos Multifuncionais (2010), documentos legais elaborados pelo Ministério da Educação, fundamentais para o entendimento do contexto educacional, social e político que assegurou o direito à educação inclusiva nos sistemas básicos regulares. Ressaltamos, insistentemente em nosso trabalho, que não desconsideramos os importantes esforços produzidos pelas políticas para garantir o direito aos estudantes que, antes, não chegavam à escola, mas, para além das políticas, nos interrogamos “[...] qual o pensamento ético que liga você ao outro" (ESTEBAN, SAMPAIO, 2012, p. 314) nas relações educativas? Seria a Sala de Recursos (apenas) o suporte técnico resultante como dispositivo de uma política que dá obrigatoriedade de aceitação do outro, pensado "com deficiência" nas escolas? O espaço pode operar de outras maneiras que não somente as consagradas pelo discurso medicalizado e majoritário da norma que encerra a condição dos outros à definição inventada de "incompletude", instaurando imperiosamente o discurso da "completude"?

Detendo-nos aqui (sucintamente) às orientações das políticas acima referenciadas - marco para o chamado campo da educação especial e inclusiva, e fruto de muitas lutas e movimentos para regulamentar e assegurar a educação especial, já que anteriormente essa modalidade de educação tradicionalmente se organizava de forma substitutiva ao ensino comum nas escolas especiais, em instituições especializadas ou em classes especiais (BRASIL, 2010), reforçando o caráter de exclusão dos ditos desviantes dos corpos normatizados na educação regular —, percebemos que a Sala de Recursos surge, nesse contexto, como um dispositivo de um Programa do Ministério da Educação para oferecer recursos, equipamentos pedagógicos e didáticos destinados a atender estudantes com necessidades específicas, nas escolas públicas regulares, por meio da política de educação inclusiva. A própria política a define como "[...] ambientes dotados de equipamentos, mobiliários, e materiais didáticos e pedagógicos para a oferta do atendimento educacional especializado" (BRASIL, 2010, p. 5), para os seguintes estudantes:

- Alunos com deficiência - aqueles que têm impedimentos de longo prazo de natureza física, intelectual, mental ou sensorial, os quais, em interação com diversas barreiras, podem ter obstruída sua participação plena e efetiva na escola e na sociedade;

- Alunos com transtornos globais do desenvolvimento - aqueles que apresentam um quadro de alterações no desenvolvimento neuropsicomotor, comprometimento nas relações sociais, na comunicação ou estereotipias motoras. Incluem-se nesta definição alunos com autismo, síndromes do espectro do autismo, psicose infantil; 
- Alunos com altas habilidades ou superdotação - aqueles que apresentam um potencial elevado e grande envolvimento com as áreas do conhecimento humano, isoladas ou combinadas: intelectual, acadêmica, liderança, psicomotora, artes e criatividade (BRASIL, 2010, p. 7).

O mesmo documento sinaliza que a Sala de Recursos surge como espaço prioritário para o desenvolvimento do atendimento educacional especializado, citando diretrizes operacionais próprias para atuação nesse ambiente, como: estratégias, metodologias, recursos, carga horária para atendimento individual ou em pequenos grupos etc. A atuação funcional indicada por meio das orientações para o atendimento na Sala de Recursos, a partir da Política de Educação Especial (2008), é algo que nos deslocou interpelações quanto ao direcionamento técnico e funcional perspectivado pela complementação ou suplementação dos estudantes:

$1^{\circ}$ Os sistemas de ensino devem matricular os estudantes com deficiência, transtornos globais do desenvolvimento e altas habilidades/superdotação nas classes comuns do ensino regular e no atendimento educacional especializado (AEE), complementar ou suplementar à escolarização, ofertado em sala de recursos multifuncionais [...] (BRASIL, 2010, p. 6, grifo nosso)

Seria a caminhada dos estudantes considerados com deficiência algo pensado como uma trajetória já propensa a encerrar-se e, por isso mesmo, faltosa, devendo, portanto, ser complementada, nomeada, fabricada? Restaria apenas uma sentença clínica para o encerramento de tais trajetórias pela "falta de aprendizado"?

Desde a concepção de trajetórias, entendemos a formação como um tipo de acompanhamento que, como processo, não assume um caráter determinado por regularidade ou fixação de uma vez por todas. Por isso, "[...] pensar en términos de trayectorias no es pensar en las biografías de cada uno de ellos solamente sino en las dimensiones que el encuentro de todos ellos abre: políticas, sociales, culturales, ideológicas, organizativas, etc.” (GRECO, NICASTRO, 2012, p. 93).

Abertas as travessias no encontro com vidas, apostamos na produção de um espaço outro para a Sala de Recursos, composto por fragilidades de experiências mediadas por múltiplas linguagens que conversam com a arte e escapam da lógica da afirmação da deficiência: brotam das conversações. Linguagens que emudecem a norma e se rendem a uma formação, talvez mais sensível ao estar com os outros. Apostamos, portanto, na linguagem do encontro, linguagem que como uma força expressiva, "[...] atravessa o sujeito no campo da vida e abastecem incertezas" (RODRIGUES, 2011, p. 17), e nos permite caminhar num plano que pensamos ser micropolítico, ou seja, um plano de produção que emerge da vida mesma, na escola.

\section{PRODUZINDO TRAJETÓRIAS ASTUCIOSAS E CONVERSANTES}

Por meio de um afortunado encontro com a obra de Certeau (2014, p. 95), expandimos conversas que se materializaram em astúcias, desenhadas entre nós nos encontros na Sala de Recursos. Diz o autor que "[...] a astúcia é possível ao fraco, e muitas vezes, como o último recurso: 
quanto mais fracas as forças submetidas à direção estratégica ${ }^{1}$, tanto mais esta estará sujeita à astúcia".

Como já dissemos até aqui, as trajetórias, não possuem um ponto linear, por isso, as experiências às quais nos referimos - aquelas que não podem ser capturadas a partir de binarismos de um tempo entendido como passado e futuro, mas quando sempre se conte um durante, alimentar-se-á de invenção e reinvenção — são, então, algo assim como efeito de um processo em curso, como travessias que, no marco de histórias, “[...] se hace pasado y futuro" (GRECO, NICASTRO, 2012) em seus encadeamentos, atravessados por conversas. Apresentamos, assim, movimentos conversantes na Sala de Recursos, dando a ver a possibilidade de produção de relações educativas talvez mais éticas e menos institucionalizadas ou funcionais. Ouçamos Certeau (2014, p. 49):

As retóricas da conversa ordinária são práticas transformadoras de "situações de palavra" de produções [...] que instaura um tecido [...] sem proprietários individuais [...] que não pertence a ninguém. A conversa é um efeito provisório e coletivo de competências na arte de manipular "lugares-comuns" e jogar com o inevitável dos acontecimentos para torná-los habitáveis.

Assim, selecionamos uma das experiências que foi narrada na pesquisa e que vai adquirindo para nós sentidos expansivos, prolongadores, não fixos. Este encontro não está narrado identicamente no mesmo formato original que aparece na pesquisa, mas mantém interpelações muito semelhantes, anunciando prolongações outras.

\section{ENTRE TRAVESSIAS ASTUCIOSAS DE PRATICANTES-DANÇANTES: TÁTICAS ENSAIADAS NA SALA DE RECURSOS MULTIFUNCIONAIS}

Criando uma trajetória de encontros ali, convidamos, naquela manhã, estudantes adolescentes, mães, funcionários e demais pessoas (totalizando um grupo de sete pessoas) para sentirmos os movimentos que o corpo produz através da dança. Ficamos em roda e em roda iniciamos alguns movimentos e gestos de dança. Supondo que, ao buscar uma atividade que envolvesse dança talvez alguém pudesse se sentir com certa timidez, vergonha, insegurança, propusemos uma roda para compartilharmos gestos de dança coletivamente pois, juntos, talvez nos sentíssemos mais descontraídos, abertos ao momento, ou até mais livres. Assim, iniciamos com a proposta de uma dança coletiva em roda, dança que ia se compondo segundo a condução de cada um dos participantes do grupo: alguém sugeria passos e, posteriormente, outro integrante aleatoriamente era convidado a dar prosseguimento, expandindo os movimentos. Sorrisos... muitos sorrisos tímidos iniciaram o momento. Traçamos alguns passos, inicialmente ao som da

\footnotetext{
${ }^{1}$ Trazemos aqui o pensamento certeauniano, no que o autor define por estratégias: "[...] ações que graças ao postulado de um lugar de poder [...] elaboram lugares teóricos (sistemas e discursos totalizantes), capazes de articular um conjunto de lugares físicos onde as forças se distribuem [...] (CERTEAU, 2014, p. 98). O sistema estratégico é, portanto, definido pelo poder, deixando de fora experiências e histórias de praticantes da vida cotidiana. No que se refere ao modo como o autor estabelece a distinção entre estratégias e astúcias e ainda táticas, percebemos que tais reflexões possibilitam outra compreensão da realidade social apresentada: de um lado, como modelo majoritário de um sistema estratégico e de outro, da potência da vida de praticantes que, com suas maneiras de fazer, reinventam seus espaços para além das relações de força dos poderosos, sendo, portanto, a astúcia, a arte dos mais fracos, porque se aproveitariam exatamente das ocasiões encontradas nas lacunas deixadas pelas estratégias — ações dos fortes.
} 
música $M y W a y^{2}$. Movimentos, talvez "descompassados" ou "dessincronizados" (tanto de minha parte quanto dos participantes) iam compondo uma dança singular que amarrava, à simplicidade da roda com mãos dadas, possibilidades outras: quem sabe tentativas semelhantes às propostas pela própria música que nos convidava na canção com a seguinte mensagem: "Por que esperar [...] pelo menos eu fiz do meu jeito!" De passos despretensiosos (quanto à técnica), mas apostando na passagem dos afetos na produção de uma dança coletiva em roda, surgiam novas danças individuais, pois, num certo momento, cada participante era convidado a se deslocar até o centro da roda, compondo o que resolvemos chamar unanimemente de: "a dança de cada um". O ambiente já estava mais cativante e caloroso, preenchido pelos sorrisos e movimentos dos participantes. Os gestos:

Uma das mães dos meninos dança apaixonadamente, movimenta e desliza em seu corpo umas fitas que compõem sua coreografia (material que disponibilizamos), parecendo obter uma sensação singular de experimentar a harmonia da música com o compasso de seus passos. Aproveita cada passo. Rouba a cena. O som da música lhe parece invadir e impulsioná-la na criação de passos. Em sintonia com o ritmo que ouvia, ela roda, mexe seus braços e sorri, chama o outro para a dança. O movimento e a melodia se misturam ao seu corpo. Uma coreografia mista de gestos e singularidades no encontro é produzida. $\mathrm{O}$ filho adolescente dessa senhora também se entrega ao momento e lança as fitas que traz em suas mãos, passando-as pelo pescoço de sua mãe e trazendo-a para dançar, numa cena que envolve uma sincronia de sensibilidade, movimentos, entrosamentos e sorrisos entre ambos. A responsável sinaliza que dança em casa com o filho e quase que diariamente, aproveita momentos assim, seja na rua ou em qualquer ambiente em que a vontade convide e completa: "lá em casa não tem isso não! A gente se diverte mesmo!" Outros participantes a observam e arriscam alguns movimentos corporais e, mesmo repetindo passos "roubados", vão movimentando fitas e percebendo movimentos possíveis com elas. Entre passos mais tímidos e outros mais entrosados, ensaiam gestos de dança. Convido um adolescente para me acompanhar. Tímido, ele arrisca pequenos movimentos com dois passos para um lado e outro. De mãos dadas comigo, a expressão de vergonha parece lhe atravessar os passos, neutralizando os movimentos endurecidos das mãos e pés que pareciam estar pesados, talvez, sem desejar o molejo permitido pela música. Parece não gostar muito do que ouvia, parece que a dança não o agradara muito naquele encontro, sua expressão foi-se tornando cada vez mais inflexível, contrária àquele momento, mas mesmo assim deixavase conduzir. Encerra-se a dança, pelo menos para nós dois. No canto da sala, outro jovem estudante conhecido pela sua simpatia e gentileza, segura a mão de uma das senhoras que estavam no encontro e, em dupla, resolvem produzir uma dança: elevam as mãos ao alto da cabeça, abaixam, levantam suas pernas e as fitas que compunham suas danças. Ele não a conhecia com afinidade para propor a dança, mas sua alegria a motivou, tornando aquele momento uma experiência singular. Posteriormente, as ações dos dois dispararam novamente a troca de pares e a dança, de coletiva, movimentou-nos em diversas possibilidades: movimentos individuais que depois se expandiram para danças em dupla e se concluiu, coletivamente, outra vez. Olho para o lado e com exceção de um adolescente, todos pulam, ensaiam novas coreografias com mãos e fitas,

${ }^{2}$ Música My Way (Meu caminho) de Calvin Harris. Essa música foi traduzida para o momento do encontro. 
levantam ambos os braços. O que dizer desse encontro? No encerramento, pensamos nos sentidos e efeitos da dança em nós, como uma atividade humana, e descobrimos que dançamos sempre com alguém, seja com algum músico que nos acompanha (mesmo estando nós sozinhos na condução de uma dança) ou com um parceiro. Pensamos, ainda, como ela traz afetações (Diário de Trajetórias).

$\mathrm{Na}$ travessia movimentada por uma dança conversante, foi possível perceber a experiência como um caminho de passos, como trajetórias. Os passos dançantes que diariamente apostamos na educação também nos remeteram àquilo que Certeau (1998, p. 176) expressa: “[...] os passos moldam espaços. Tecem os lugares". A conversa com essa experiência expandiu-nos o pensamento sobre a noção de espaço apresentado por Certeau. Este autor, analogamente, desenvolve suas reflexões considerando o espaço da cidade como um lugar inicialmente organizado sob um discurso urbanístico ocidental, podendo, todavia, também operar como outro lugar próprio, produzido por seus "usuários" que jogam, astutamente com esse lugar, e o fazem outro. Entre a travessia do encontro narrado e o pensamento de Certeau, fizemos conexões para pensar que o espaço é aquilo que seus usuários fazem dele, portanto:

[...] seja nos limiares de uma cidade (como analisa Certeau, 1998) ou nas brechas de encontros na Sala de Recursos Multifuncionais — onde acaba a visibilidade das políticas públicas, visto que se tem um conhecimento geral/oficial do espaço e não necessariamente do singular/cotidiano - , nós, caminhantes, pedestres, professores, estudantes e outros "jogamos com os espaços" (p. 171) e invertemos as lógicas balizadas por ações oficiais, reinventando "maneiras de fazer" e ações que criam um jogo de forma que, no encontro, não se faz mais notar (apenas) por técnicas, mas por relações com lógicas próprias que não obedecem "a lei do lugar, não se definem por esse (CERTEAU, 1998, p. 92)". (MONTEIRO, 2019, p. 92)

Nesse sentido, os processos caminhatórios pensados para nossos encontros na Sala de Recursos não se guiavam por "[...] caminhos considerados lícitos ou obrigatórios" (CERTEAU, 1998, p. 178). Os passos, talvez descompassados, o andar, o ato de dançar compõem outro espaço, o caminhante [o dançante] transgride o sistema e o altera, e não se permite mais pensar (apenas) em caminhos demarcados por passos institucionalizados - como por vezes se pauta a Sala de Recursos que, sob o ritmo da normalização, também atua como marcadora dos corpos e das relações. A partir de outra espacialidade criada por nós, habitantes/dançantes que têm seus próprios modos de fazer, suas próprias lógicas e temporalidades, ressignificamos os sentidos e produzimos uma tática ${ }^{3}$ - dança, transformando um espaço que, agora, já não é traduzido pela lógica da complementação que, preliminarmente, pensa o outro de forma documentada, deficiente, obsessiva, sobre aquilo que poderá, ou não, ou poderão ser, suas trajetórias pela escola. Não caminhamos-dançamos com eles/elas guiados pela lógica normatizada que reconhece o outro pela medíocre normalidade que o nomeia esperando, talvez, uma suposta cura ou redução de ausências, faltas. O pensamento que nos tomou ali possibilitou-nos pensar o lugar como de experiência, de encontro, como espaço próprio para ensaiar maneiras de fazer [dançar], gestos outros igualmente

\footnotetext{
${ }^{3}$ A noção de tática para Certeau (1998, p. 100) está relacionada a um “[...] movimento dentro do campo de ação do inimigo e no espaço por ele controlado". Ela aproveita as ocasiões com astúcia usando os espaços nas "[...] lacunas das estratégias dos poderosos/sábios". Em suma, a tática se constitui na "arte do fraco" (p. 101), pois quanto menos poder se tem, mais astúcia é possível, já que escapa ao campo de visibilidade nesse jogo.
} 
impossíveis de gerir, apostas de passeantes [dançantes] que mudam o passo institucional de um sistema regular e o transformam "[...] em alguma outra coisa que não mais aquela já consagrada para complementar ou suplementar trajetórias ditas 'desviantes"'.

Semelhantemente difícil, foi sentir a resistência do adolescente que demonstrava certo "desagrado" ao dançarmos, pois pela reverberação da experiência, refleti que o "estranhamento" mútuo — tanto de minha parte que não entendeu a relação de "desagrado" do jovem quanto à do jovem que "rejeitava" meu convite para a dança — representam passos de uma relação que se forja na alteridade, ou seja, em uma caminhada que se produza na alteridade, talvez, a experiência com alguém que se nega a fazer algo que todos estão fazendo, "daqueles e daquelas que nunca são o que deveriam ser, pois sempre estão sendo para os outros, aquilo que alguém jamais desejaria ser, e bem se sabe que alguém é na medida do desejo dos outros" (PEREZ DE LARA, 2003, p. 12) represente nossa precipitada vontade de esperar que na educação habitem apenas relações harmônicas, confortáveis, que nos deem segurança ao estar juntos no encontro (MONTEIRO, 2019, p. 81).

Talvez esse encontro tenha se traduzido para o jovem numa experiência "desconversante" com a dança, mas certamente conversada, habitada, estranhada com outros. Aos nossos olhos, o encontro representou uma interessante conversa, bem como cita Larrosa (2003) a respeito de ser uma relação conversacional "[...] cheia de diferenças [...] tensão entre as diferenças [...] que pode manter dúvidas até o final”, porém cada vez mais “[...] sensíveis" (LARROSA, 2003, p. 2013). Ali, a conversa não era preenchida da necessidade de cumprir um atendimento especializado muito mais técnico do que sensível. Esse encontro marcou a tentativa de ensaiarmos conversas reinventadas por uma pedagogia guiada pelo desejo de ensaiar a própria educação e a própria vida mesma, e menos as lógicas jurídicas que anunciam um caminho já dado.

\section{CONSIDERAÇÕES FINAIS}

Esta composição não apresenta conclusões, ela evoca um movimento caminhatório em construção, ressonâncias de experiências de uma pesquisa. Se podemos falar assim, este trabalho tratou de ensaiar experiências entre caminhares que não têm medo da diferença e nos produzem cotidianamente pelos deslocamentos no chão da escola, fazendo-nos questionar a produção da norma encarnada, as relações educativas junto a trajetórias interditadas e, por isso, desautorizadas de diferir.

O que vimos apontando em todo o trabalho é que as trajetórias estudantis jamais podem ser fabricadas, segundo concepções medicalizadas, afirmadas por diagnósticos que mascaram - e utilizam uma lupa cada vez mais clínica, para anular a diferença. Por isso, a produção de encontros na Sala de Recursos, não objetivou, neste trabalho, narrar um atendimento técnico, algo complementar do Atendimento Educacional Especializado. Não desconsideramos a importância dessa ação no campo educativo mas, aqui, optamos por ensaiar astúcias como abertura para a conversa, experimentando outras formas de estar juntos. A aposta que fizemos não se pretendeu ser algo desqualificador do trabalho realizado pelos professores que atuam neste espaço, mas a abertura de uma experiência-conversa que não se guie tanto pelas dimensões técnicas, na composição de fazeres singulares com vidas. 
Supondo que saber sobre trajetórias é já tê-las definido e pô-las como encerradas numa caminhada - que só se pode produzir por meio de um durante —, preferimos convidar o leitor a seguir conosco pelos caminhos inconclusivos do fazer-se na docência, passagem essa sempre ensaiada entre travessias.

\section{REFERÊNCIAS}

BRASIL. Ministério da Educação. Politica Nacional de Educação Especial na Perspectiva da Educação Inclusiva, 2008.

BRASIL, Ministério da Educação. Manual de Orientação: Programa de Implantação de Salas de Recursos Multifuncionais, 2010.

CERTEAU, Michel de. A invenção do cotidiano 1. Artes de fazer. 3. ed. Petrópolis, Rio de Janeiro: Vozes, 1998.

CERTEAU, Michel de. A invenção do cotidiano 1. Artes de fazer. Trad. Ephraim Ferreira Alves. 22. ed. Petrópolis, Rio de Janeiro: Vozes, 2014.

CLÍMACO, Júlia. Discursos Jurídicos e Pedagógicos sobre a Diferença na Educação Especial, 174 fls. Dissertação (Mestrado em Ciências Sociais) - Facultad Latino Americana de Ciências Sociales, Sede Académica, Argentina, 2010.

ESTEBAN, Maria Teresa; SAMPAIO, Carmem. Provocações para pensar em uma educação outra: conversa com Carlos Skliar. Revista Teias. v. 13, n. 30, p. 311-325, 2012.

LARROSA, Jorge. A arte da conversa: epílogo. In: SKLIAR, Carlos. Pedagogia (improvável) da diferença. E se o outro não estivesse aí? Rio de Janeiro: DP\&A, 2003. p. 211-216.

LARROSA, Jorge. O ensaio e a escrita acadêmica. In: CALLAI, Cristiana; RIBETTO, Anelice. (org.). Uma escrita acadêmica outra: ensaios, experiências e invenções. Rio de Janeiro: Lamparina, 2016. p. 17-30.

MOYSÉS, Maria Aparecida. A institucionalização invisivel: crianças que não aprendem na escola. Campinas. São Paulo: Mercado de Letras, Fapesp, 2001.

MONTEIRO, Raquel. Diariando trajetórias e encontros na Sala de Recursos Multifuncionais: uma experiência formativa. 100fls. Dissertação (Mestrado em Educação) - Universidade do Estado do Rio de Janeiro/UERJ-FFP, 2019.

NICASTRO, Sandra; GRECO, María Beatriz. Entre trayectorias: escenas y pensamentos em espacios de formación. 1. ed. Rosario: Homo Sapiens Ediciones, 2012.

PEREZ DE LARA, Nuria. Pensar muito além do que já é dado, pensar a mesmidade a partir do outro que está em mim. In: SKLIAR, Carlos. Pedagogia (improvável) da diferença. E se o outro não estivesse aí? Rio de Janeiro: DP\&A, 2003. p. 11-15.

RODRIGUES, Hélio. Vertigens do vazio. Rio de Janeiro: Livre expressão, 2011.

SKLIAR, Carlos. Poner en tela de juicio la normalidad, no la anormalidad. Políticas y falta de políticas en relación con las diferencias en educación. Revista Educación y Pedagogía, v. 27, n. 41, 2005.

SKLIAR, Carlos. Conversar e conviver com desconhecidos. In: FONTOURA, Helena (org.) Políticas públicas, movimentos sociais. Desafios à pós-graduação em educação em suas múltiplas dimensões. Rio de Janeiro: Anped Sudeste. Livro 3, 2011. p. 27-37.

SKLIAR, Carlos. O ensinar enquanto travessia: linguagens, leituras, escritas e alteridades para uma poética da educação. Salvador: EDUFBA, 2014a. 
SKLIAR, Carlos. Lo anónimo, lo efímero y lo mínimo: prácticas educativas entre desconocidos. In: RIBETTO, Anelice (org.). Politicas, poéticas e práticas pedagógicas (com minúsculas). 1. ed. Rio de Janeiro: Lamparina, FAPERJ, 2014b. p. 72-82.

Submetido em fevereiro de 2021 Aprovado em abril de 2021

\section{Informações das autoras}

Anelice Ribetto

Universidade do Estado do Rio de Janeiro (UERJ)

E-mail: anelatina@gmail.com

ORCID: https://orcid.org/ORCID: 0000-0003-1097-4880

Link Lattes: http://lattes.cnpq.br/1137124063566744

Raquel Rosa Reis Monteiro

Prefeitura Municipal de São Gonçalo e de Araruama, Rio de Janeiro.

E-mail: raquel.rosa.reis@gmail.com

ORCID: https://orcid.org/0000-0001-9550-6183

Link Lattes: http://lattes.cnpq.br/0204008343070760 